Supporting Information for

\title{
Programmable Modulation of Membrane Permeability of Proteinosome upon Multiple Stimuli Responses
}

Pei Zhou, Xiaoman Liu*, Guangyu Wu, Ping Wen, Lei Wang, Yudong Huang and Xin Huang*

MIIT Key Laboratory of Critical Materials Technology for New Energy Conversion and Storage, State Key Laboratory of Urban Water Resource and Environment, School of Chemistry and Chemical Engineering, Harbin Institute of Technology, Harbin, 150001, China.

*E-mail:liuxiaoman@hit.edu.cn; xinhuang@hit.edu.cn.

\section{SUPPLEMENTARY METHODS}

\subsection{Characterization methods}

${ }^{1} \mathrm{H}$ NMR spectra were recorded on Bruker Advance-400 MHz spectrometer, with $\mathrm{CDCl}_{3}$ as solvents at room temperature. Chemical shifts $(\delta)$ were expressed in ppm and coupling constants $(\mathrm{J})$ in Hertz. Transmission electron microscopy (TEM) analysis was undertaken on a JEM-1400. TEM using a LaB6 filament at $120 \mathrm{kV}$ in bright field mode. Samples were prepared by adding one drop of proteinosome solution $(0.1 \mathrm{mg} / \mathrm{mL})$ onto a $300 \mathrm{mesh}$, carbon film coated copper grid and the specimens were then dried in vaccum for one day. SEM images were obtained on a HITACHI UHR FE-SEM SU8000 with the samples sputter-coated with $10 \mathrm{~nm}$ platinum. Optical and fluorescence microscopy was performed on a Leica DMI8 manual inverted fluorescence microscope at 10x, 20x, 40x and 100x magnification. Fluorescence measurements were performed on a PerkinElmer spectrofluorometer 
(LS-55, USA). UV-vis spectra were measured on a PerkinElmer spectrophotometer (Lambda 750S, USA). The average particle size and size distribution of the capsules (0.2 mg/mL, pH 6.8, 5.0 mM PBS buffer) were characterized by dynamic light scattering (DLS) with an ALV-5000/E DLS instrument (Malvern Instruments, UK) at a fixed scattering angle of $90^{\circ}$, after being filtered by $0.45 \mu \mathrm{m}$ Milli-pore filters. Zeta potential studies of sample solutions $(0.2 \mathrm{mg} / \mathrm{mL}, \mathrm{pH} 6.8,5.0 \mathrm{mM}$ PBS buffer $)$ were carried out at $25^{\circ} \mathrm{C}$ using a ZETASIZER Nano series instrument (Malvern Instruments, UK). Circular dichroism (CD) spectra of the native and released insulin from the capsules at 200-300 $\mathrm{nm}$ in PBS buffer were obtained by a CD spectropolarimeter (Jasco-715, JPN) at room temperature. The $\mathrm{pH}$ measurements were made with a SevenCompact meter (METTLER TOLEDO, SUI). Oscillator was employed by a VORTEX instrument (IKA, GER). Assimilated solutions were executed by pipettors (GILSON, FRA).

\subsection{Materials}

1-Propanethiol (Aladdin, 99\%), carbon disulfide (Sigma, 99\%), potassium ferricyanide $\left(\mathrm{K}_{3} \mathrm{Fe}(\mathrm{CN})_{6}\right.$, Aladdin, 99\%), 4,4'-azobis (4-cyanovaleric acid) (ACVA, Sigma, 98\%), 2,2'-Dithiodipyridine (Aladdin, 98\%), 2-Mercaptoethanol (Sigma, 99\%). N'-dicyclohexylcarbodiimide (DCC, Fluka, 99 \%), 4- (dimethylamino)pyridine (DMAP, Aldrich 99\%), Tris(2,2'-bipyridine) dichlororuthenium(II) hexahydrate (Aladdin, 98\%), N-isopropylacrylamide (NIPAAm, Sigma, $98 \%$ ) was recrystallized twice in hexane and toluene prior to use. PEGylated bis(sulfosuccinimidyl)suberate 
(BS(PEG)5, Mw 532, Sigma, 98\%), 1,6-diaminohexane (Sigma, 98\%), 2,4,6-trinitrobenzene sulfonic acid (TNBSA) solution (5\% (w/v) in $\mathrm{H}_{2} \mathrm{O}$, Sigma), 5,5-Dithio bis-(2-nitrobenzoic acid) (DTNB) (Sigma, $\geq 98 \%$ ), 2-ethyl-1-hexanol (Sigma, $\geq 98 \%$ ), albumin from bovine serum $($ BSA, isoelectric point $=4.6)($ Sigma, $\geq 98 \%, \mathrm{Mw} \sim 66 \mathrm{kDa}$ ), 2-iminothiolane hydrochloride (2-IT, $\geq 98 \%$, powder from Sigma) were used as received without further purification.

\subsection{Experimental section}

\subsubsection{Synthesis of mercaptopyridine-activated trithiol-RAFT agent 2-(pyridin-2- yldisulfanyl) ethyl 4-cyano-4-(((propylthio)carbonothioyl)thio) pentanoate}

A solution of 2-(2-dimercaptopyridine) ethanol (4.01 g, $14.3 \mathrm{mmol})$ and 4-cyano-4-(propylsulfanylthiocarbonyl) sulfanylpentanoic acid $(4.50 \mathrm{~g}, 37.8 \mathrm{mmol})$ in 1,4-dioxane $(200 \mathrm{~mL})$ was degassed by nitrogen for 30 mins. Then $\mathrm{N}$, N'-dicyclohexylcarbodiimide (DCC, $6.82 \mathrm{~g}, 33.0 \mathrm{mmol}$ ) and 4-(dimethylamino) pyridine (DMAP, $0.10 \mathrm{~g}, 0.82 \mathrm{mmol})$ dissolved in 1,4-dioxane $(100 \mathrm{~mL})$ were added slowly at room temperature under rigorous stirring. After $20 \mathrm{~h}$, the reaction mixture was filtered and concentrated. The product was obtained as a red liquid. ${ }^{1} \mathrm{H}$ NMR $\left(400 \mathrm{MHz}, \mathrm{CDCl}_{3}\right) \delta=8.47(\mathrm{~d}, 1 \mathrm{H}), 7.84(\mathrm{~m}, 1 \mathrm{H}), 3.32(7.78,1 \mathrm{H}), 7.26(\mathrm{~m}, 1 \mathrm{H}), 4.29$ $(\mathrm{t}, 2 \mathrm{H}), 3.37(\mathrm{t}, 2 \mathrm{H}), 3.13(\mathrm{t}, 2 \mathrm{H}), 2.55(\mathrm{t}, 2 \mathrm{H}), 2.47(\mathrm{~m}, 1 \mathrm{H}), 2.39(\mathrm{~m}, 1 \mathrm{H}), 1.85(\mathrm{~s}$, $3 \mathrm{H}), 1.68(\mathrm{~m}, 2 \mathrm{H}), 0.96(\mathrm{t}, 3 \mathrm{H})$.

\subsubsection{Synthesis of end-capped mercaptopyridine-activated PNIPAAm by RAFT}




\section{polymerization}

Mercaptopyridine-activated trithiol-RAFT agent $(3 \quad \mathrm{mg}, 6.7 \mu \mathrm{mol})$, tris(2,2'-bipyridine) dichlororuthenium(II) hexahydrate $(0.1 \mathrm{mg}, 0.13 \mu \mathrm{mol})$, NIPAAm (600 mg, $5.31 \mathrm{mmol})$ and acetonitrile $(3 \mathrm{~mL})$ were added to a $10 \mathrm{~mL}$ of round-bottom flask. The flask was then sealed and the solution was degassed via four freeze pump-thaw cycles. The polymerization was carried out at UV-irradiation (395nm) for $24 \mathrm{~h}$ (conversion 80\%), and purified by three times precipitation in diethyl ether/hexane (2:1 volume ratio). The obtained polymer was characterized by ${ }^{1} \mathrm{H}$ NMR spectroscopy in $\mathrm{CDCl}_{3}$. The proton signal $(\delta, 4 \mathrm{H}$. 7.0-8.5 ppm) from the pyridine at

the end of the PNIPAAm chain was clearly visible in the ${ }^{1} \mathrm{H}$ NMR spectrum. The molecular weight of the obtained PNIPAAm was determined by ${ }^{1} \mathrm{H}$ NMR by comparing the integral of the proton of the $\mathrm{CH}$ signal at $\delta=7.75 \mathrm{ppm}$ in pyridine with that of the characteristic $\mathrm{CH}$ signal at $\delta=4.0 \mathrm{ppm}$ in the repeat unit of NIPAAm (Mn $18000 \mathrm{~g} / \mathrm{mol})$.

Fluorescein-labelled end-capped mercaptopyridine-activated PNIPAAm was synthesized according to the above procedure, except that $10 \mathrm{mg}$ of fluorescein O-methacrylate was additionally added into the reaction solution.

\subsubsection{Synthesis of the cationized bovine serum albumin $\left(\mathrm{BSA}-\mathrm{NH}_{2}\right)$}

Cationized bovine serum albumin $\left(\mathrm{BSA}-\mathrm{NH}_{2}\right)$ was synthesized by carbodiimide activated conjugation of 1, 6-diaminohexane to aspartic and glutamic acid residues on 
the external surface of the protein. For this, a solution of 1, 6-diaminohexane (1.5 g, $12.9 \mathrm{mmol}$ ) was adjusted to $\mathrm{pH} 6.5$ using $5 \mathrm{M} \mathrm{HCl}$ and added dropwise to a stirred solution of the protein $(200 \mathrm{mg}, 2.98 \mu \mathrm{mol})$. The coupling reaction was initiated by adding N'-ethyl-N'-(3-(dimethylamino) propyl) carbodiimide hydrochloride (EDAC, $100 \mathrm{mg}$ ) immediately and again (50 mg) after $5 \mathrm{~h}$. The $\mathrm{pH}$ value was maintained at 6.5 using dilute $\mathrm{HCl}$, and the solution was stirred for a further $6 \mathrm{~h}$. The solution was then centrifuged to remove any precipitate, and the supernatant was dialyzed (dialysis tubing $12-14$ kDa MWCO) extensively against Milli-Q water.

\subsubsection{Synthesis of the thiolated bovine serum albumin (BSA-SH).}

BSA- $\mathrm{NH}_{2}$ was dissolved in $50 \mathrm{mM}$ sodium phosphate buffer $(\mathrm{pH} 8$, including 5 $\mathrm{mM}$ EDTA) and stirred gently at $0^{\circ} \mathrm{C}$ on ice. Subsequently, an aqueous solution of 2-IT $\left(20 \mathrm{mg} \mathrm{mL}^{-1}\right)$ was added drop-wise to the BSA-NH $\mathrm{N}_{2}$ solution. After 2 hours, the mixture was brought back to room temperature. The product was first dialyzed against 10mMHEPES buffer ( $\mathrm{pH} 7$ ) three times over 24 hours and then, against Milli-Q water three times over 2 days at $4^{\circ} \mathrm{C}$. Finally, BSA-SH was lyophilized and stored at $-20^{\circ} \mathrm{C}$.

\subsubsection{Synthesis of BSA-SH/PNIPAAm nanoconjugates.}

Mercaptopyridine-activated PNIPAAm was added to a stirred solution of BSA-SH (10 $\mathrm{mg}$ in $5 \mathrm{~mL}$ of PBS buffer at $\mathrm{pH} 8.0$ ). The mixed solution was stirred for $12 \mathrm{~h}$, and then purified by using a centrifugal filter (MWCO $50 \mathrm{kDa}$ ) to remove any unreacted PNIPAAm and salts. After freeze-drying, the BSA-SH/PNIPAAm conjugate was 
obtained.

\subsubsection{Preparation of proteinosomes.}

Proteinosomes were prepared by mixing an aqueous BSA-SH/PNIPAAm solution with 2-ethyl-1-hexanol followed by shaking the mixture by hand for $10 \mathrm{~s}$. The samples were prepared at a constant aqueous/oil volume fraction of 0.06 . Typically, $0.06 \mathrm{ml}$ of aqueous BSA-SH/PNIPAAm $(4.0 \mathrm{mg} / \mathrm{ml}, \mathrm{pH} 8.5$, sodium carbonate buffer $)$ were mixed with $1.0 \mathrm{ml}$ of the oil. The proteinosomes were then cross-linked in the continuous oil phase by addition of PEG-bis(N-succinimidyl succinate) $(0.5 \mathrm{mg})$, which reacted with free remanent primary amine groups of BSA. Transfer of the cross-linked proteinosomes into water was achieved as follows. After $3 \mathrm{~h}$ sedimentation, the upper clear oil layer was discarded and $1 \mathrm{ml}$ of $65 \%$ ethanol was added and the emulsion was gently shaken. The dispersion was then dialysed against $65 \%$ ethanol for $5 \mathrm{~h}, 50 \%$ ethanol for $2 \mathrm{~h}, 30 \%$ ethanol for $2 \mathrm{~h}$ and Milli-Q water for 2 days to complete the phase transfer process. Proteinosomes comprising encapsulated components include dyes (FITC-Dextran, RhB-Dextran), which were added to the aqueous BSA-SH/PNIPAAm solution before mixing with the oil phase.

\subsubsection{Determination of primary amine group on the surface of $\mathrm{BSA}-\mathrm{NH}_{2}$ by TNBSA measurement}

2,4,6-Trinitrobenzene sulfonic acid (TNBSA) is a rapid and sensitive assay reagent for the determination of free primary amine groups. Primary amines, upon reaction 
with TNBSA, form highly chromogenic derivatives, which can be measured at 348 $\mathrm{nm}$ by UV-vis spectroscopy. Typically, sample solutions of $\mathrm{BSA}-\mathrm{NH}_{2}(0.001-0.1$ $\mathrm{mg} / \mathrm{mL}$ ) were prepared in $0.1 \mathrm{M}$ sodium bicarbonate buffer ( $\mathrm{pH} 8.5$ ). The supplied $5 \%$ TNBSA solution was diluted 250-fold in $0.1 \mathrm{M}$ sodium bicarbonate buffer ( $\mathrm{pH} 8.5$ ). Then the diluted TNBSA solution $(0.25 \mathrm{~mL})$ was added to $0.4 \mathrm{~mL}$ of sample solution, and incubated at $37{ }^{\circ} \mathrm{C}$ for 2 hours. Next, $0.2 \mathrm{M} \mathrm{HCl}(0.65 \mathrm{~mL})$ was added to each sample to stop the reaction. The UV-vis spectra of the solutions were recorded (Figure S5b). To determine the concentration of amine, a standard primary amine absorbance curve was performed based on the same procedure using glycine as a standard compound (Figure S5a). In comparison with glycine, the number of primary amine groups per $\mathrm{BSA}-\mathrm{NH}_{2}$ was determined to be $c a .90$ in average (Table $\mathrm{S} 1$ ).

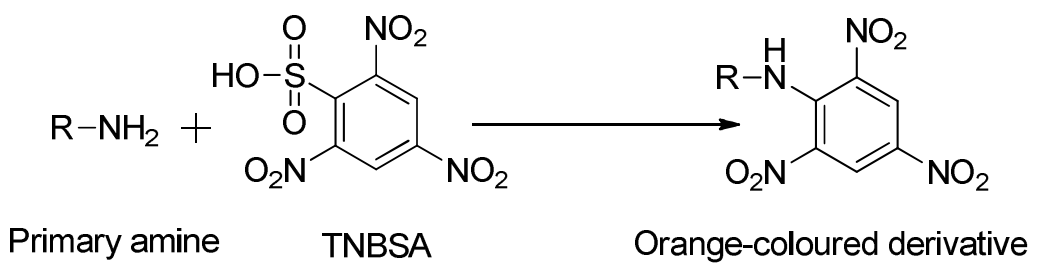

\subsubsection{Determination of primary sulfydryl group on the surface of BSA-SH by DTNB measurement}

This is a standard "Ellman's Test" for the determination of free thiols. It works well for small peptides and proteins synthesized using standard solid phase synthetic methods. Peptides from these synthsis are usually in their reduced form, and are usually stable to oxidation in acidic solutions. In detail, $50 \mathrm{mM}$ sodium acetate (NaAc) and $2 \mathrm{mM}$ DTNB was mixed in $\mathrm{H}_{2} \mathrm{O}$, and keep refrigerated. Prepare the DTNB working reagent: (per sample) add $50 \mu \mathrm{L}$ of the DTNB solution, $100 \mu \mathrm{L}$ of PBS 
solution ( $\mathrm{pH} 7.4$ ), and $840 \mu \mathrm{L}$ of water (final volume will be $1000 \mu \mathrm{L}$ with $10 \mu \mathrm{L}$ of sample). Mix the solution carefully using a pipette. Place the cuvette into a UV spectrophotometer and measure the background. Add $10 \mu \mathrm{L}$ of sample solution (or 10 $\mu \mathrm{L}$ of sample buffer for the blank test, or $10 \mu \mathrm{L}$ of standards) to $990 \mu \mathrm{L}$ of DTNB reagent. Mix well and incubate $5 \mathrm{~min}$ at room temperature. Measure the optical absorbance at $418 \mathrm{~nm}$. Calculate SH content and the primary sulfydryl groups per BSA-SH was determined to be 6 on average.

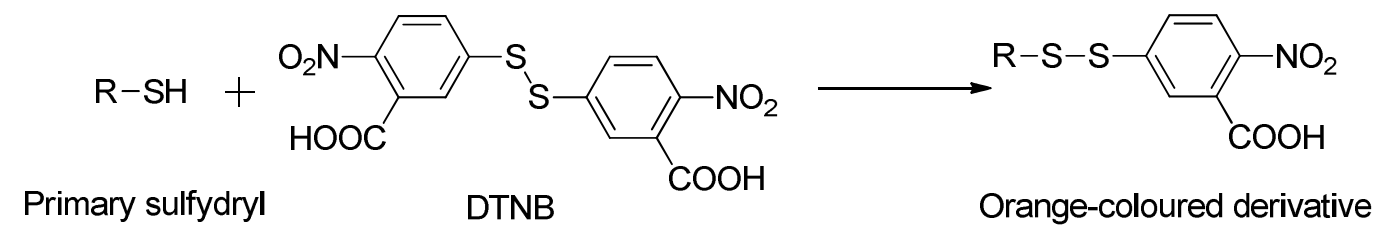




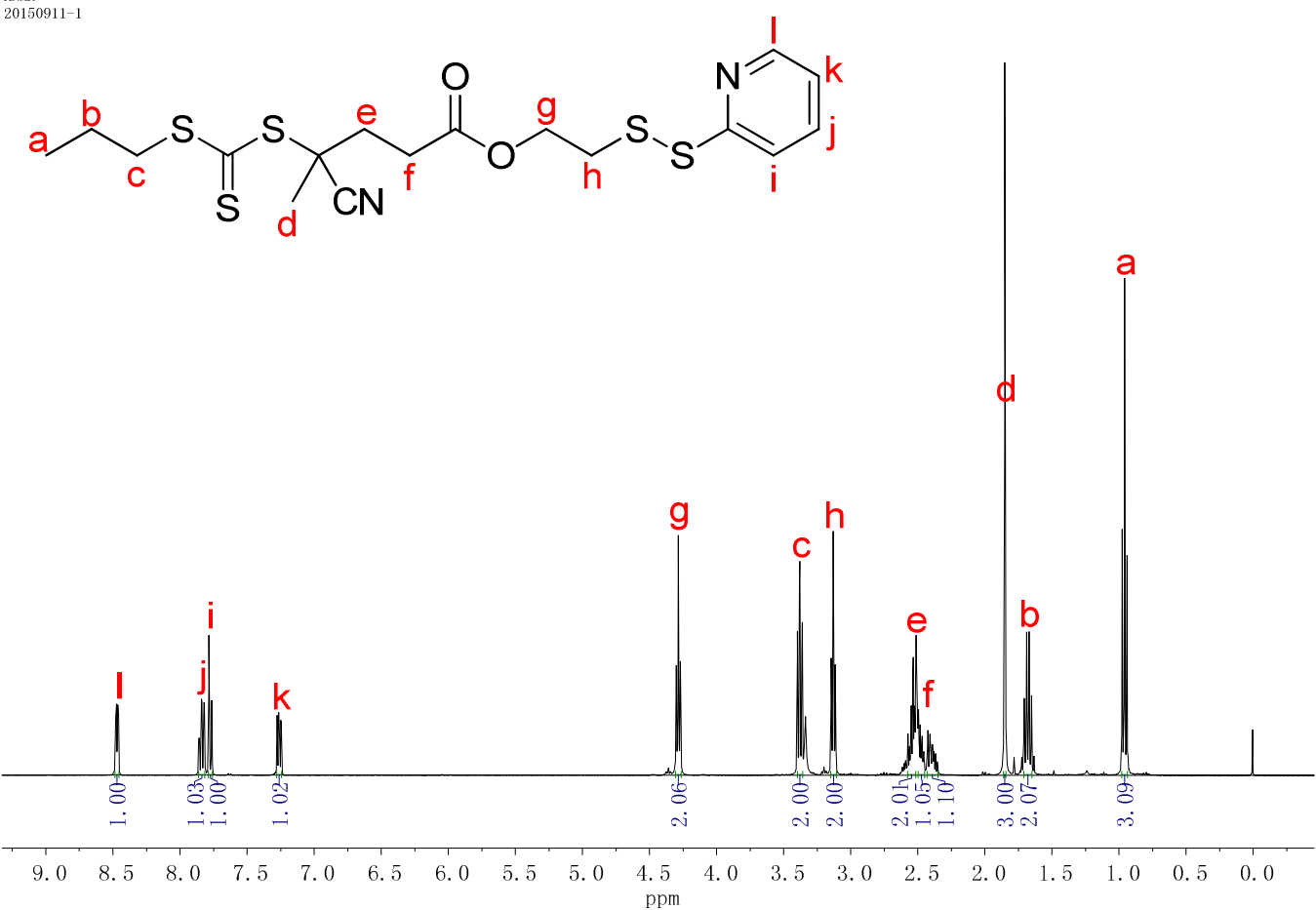

Supplementary Figure S1. ${ }^{1} \mathrm{H}$ NMR spectrum of end-capped pyridine disulfide-RAFT agent 2-(pyridin-2-yldisulfanyl)ethyl 4-cyano-4-(((propylthio) carbonothioyl)thio)pentanoate in DMSO- $d_{6}, 400 \mathrm{MHz}$. 


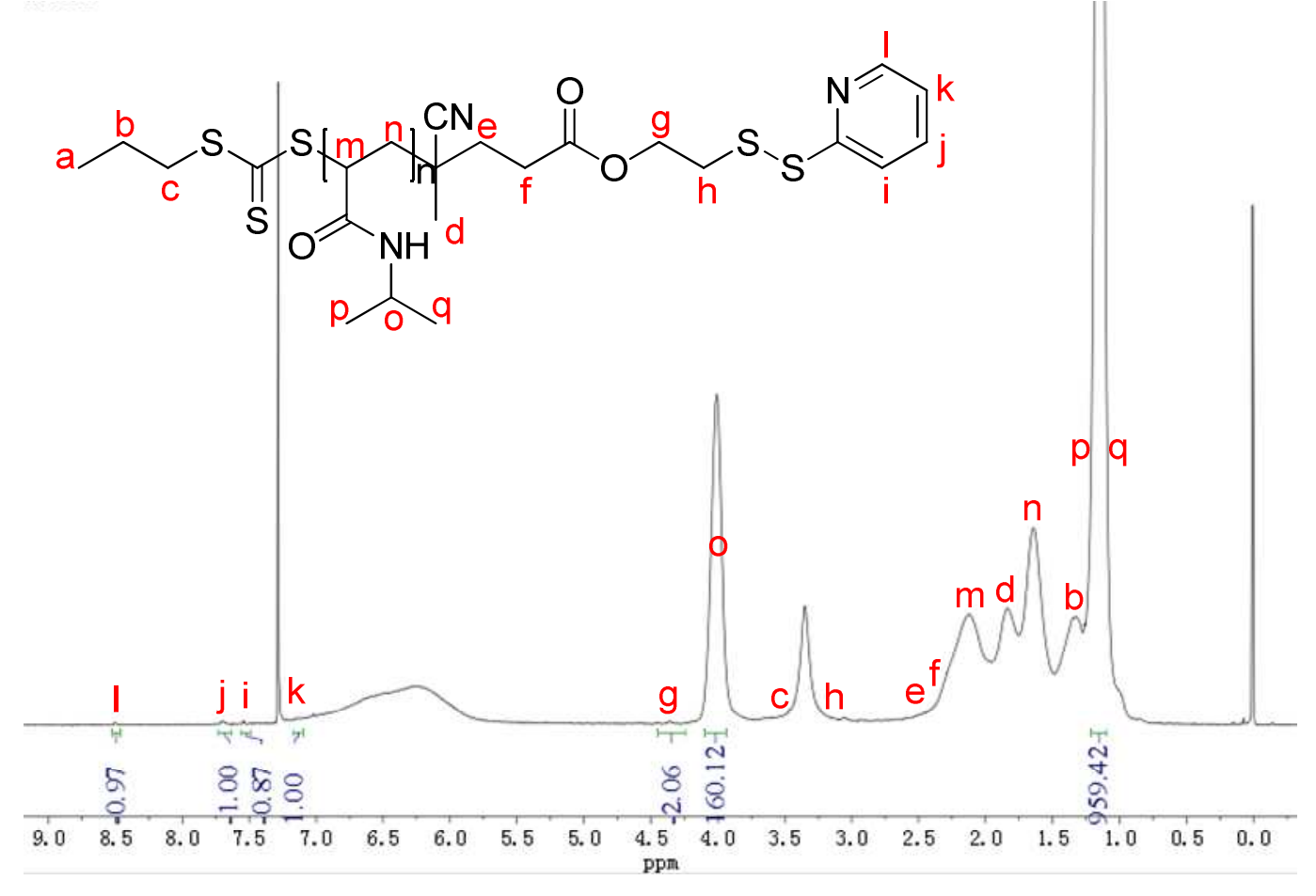

Supplementary Figure S2. ${ }^{1} \mathrm{H}$ NMR spectrum of end-capped pyridine disulfide modified PNIPAAm (Mn $18000 \mathrm{~g} / \mathrm{mol})$ in $\mathrm{CDCl}_{3}, 400 \mathrm{MHz}$. 

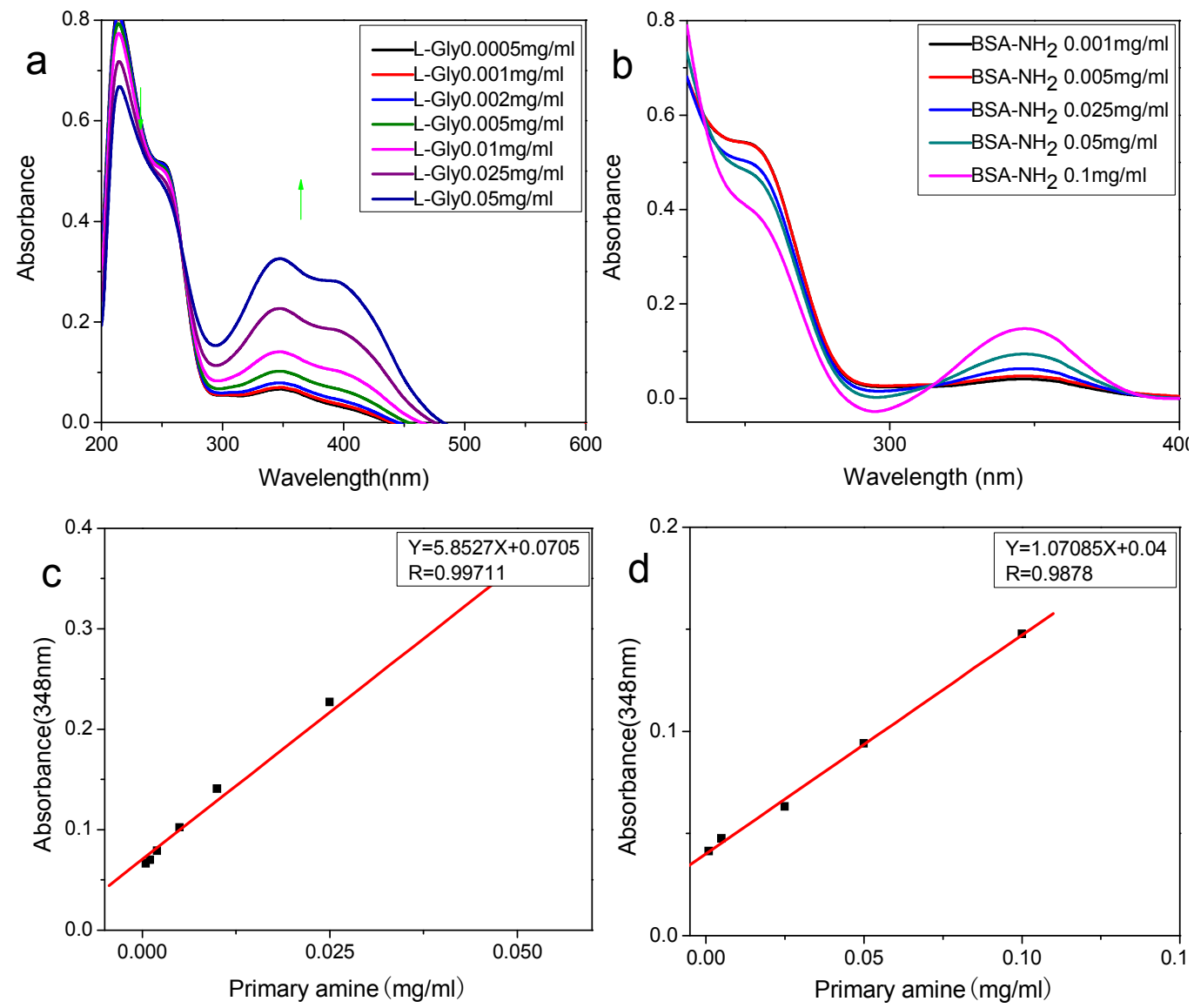

Supplementary Figure S3. (a,b) UV-Vis spectra obtained for TNBSA/glycine control assay and $\mathrm{BSA}-\mathrm{NH}_{2}$, (c,d) corresponding calibration curve based on plotting the absorbance at $348 \mathrm{~nm}$ against the concentration of primary amine. Supplementary Table 1 is the number of primary amine groups (ca. 90) in BSA-NH $\mathrm{NH}_{2}$.

Supplementary Table 1: Number of primary amine groups in BSA-NH 2 .

\begin{tabular}{|c|c|c|c|}
\hline $\mathrm{A}_{348 \mathrm{~nm}}$ & $\begin{array}{c}\text { Glycine } \\
(\mathrm{mM} / \mathrm{ml})\end{array}$ & $\begin{array}{c}\mathrm{BSA}-\mathrm{NH}_{2} \\
(\mathrm{mM} / \mathrm{ml})\end{array}$ & $\begin{array}{c}\text { Number } \\
\left(-\mathrm{NH}_{2}\right)\end{array}$ \\
\hline 0.09402 & $0.004 / 75$ & $0.05 / 68000$ & 72.5 \\
\hline 0.11927 & $0.008 / 75$ & $0.075 / 68000$ & 96.7 \\
\hline 0.14764 & $0.012 / 75$ & $0.1 / 68000$ & 108.8 \\
\hline
\end{tabular}



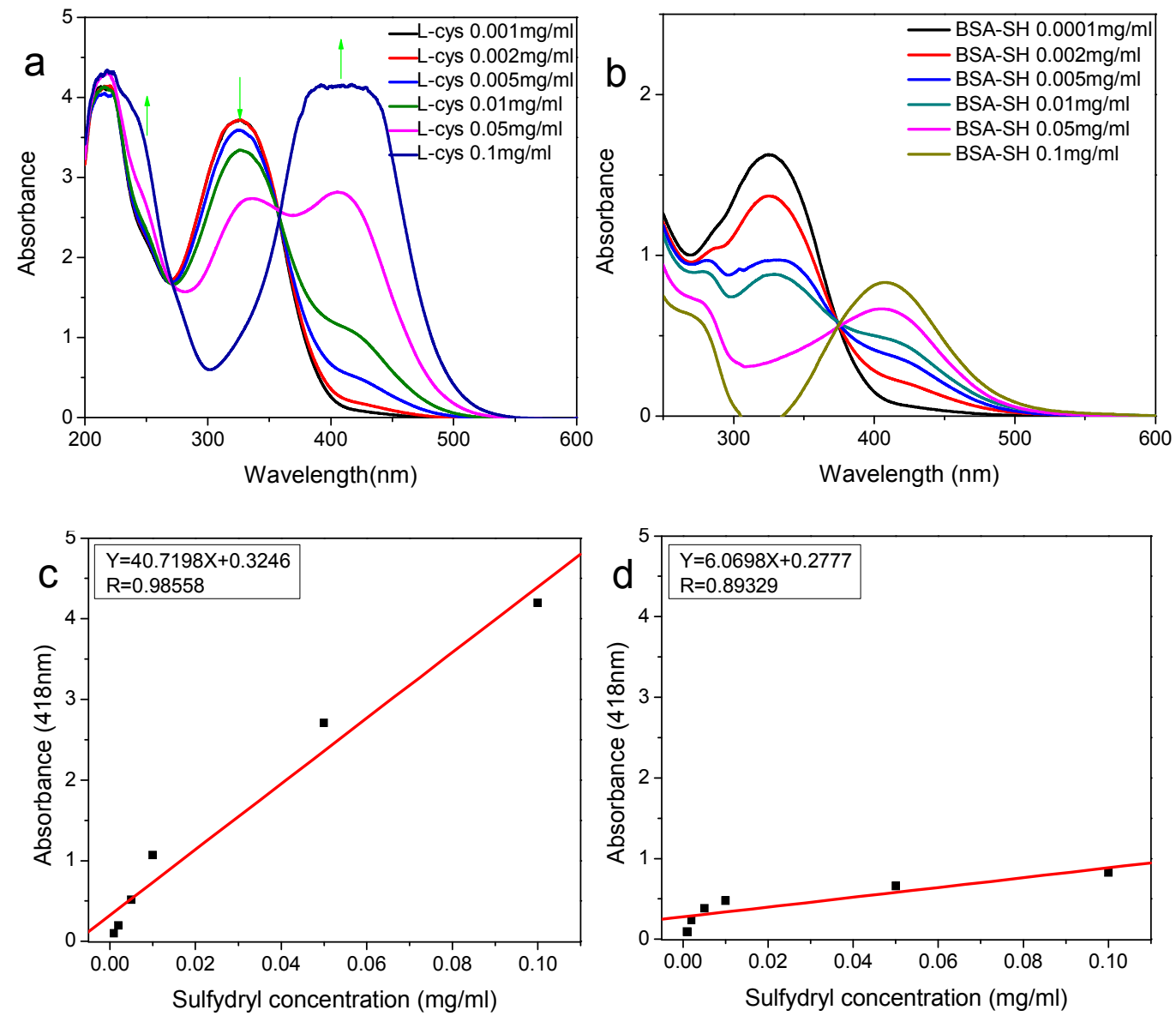

Supplementary Figure S4. (a,b) UV-Vis spectra obtained for DTNB/ L-cysteine control assay and BSA-SH, (c,d) corresponding calibration curve based on plotting the absorbance at $418 \mathrm{~nm}$ against the concentration of active sulfydryl. Supplementary Table 2 is the number of primary sulfydryl groups (ca. 6) in BSA-SH.

Supplementary Table 2: Number of linked primary sulfydryl groups in BSA-SH.

\begin{tabular}{|c|c|c|c|}
\hline $\mathrm{A}_{418 \mathrm{~nm}}$ & $\begin{array}{c}\text { L-cysteine } \\
(\mathrm{mM} / \mathrm{ml})\end{array}$ & $\begin{array}{c}\mathrm{BSA}-\mathrm{SH} \\
(\mathrm{mM} / \mathrm{ml})\end{array}$ & $\begin{array}{c}\text { Number } \\
(-\mathrm{SH})\end{array}$ \\
\hline 0.09352 & $0.001 / 121$ & $0.1 / 68000$ & 5.6 \\
\hline 0.4796 & $0.00381 / 121$ & $0.4 / 68000$ & 5.35 \\
\hline 0.82893 & $0.01238 / 121$ & $1 / 68000$ & 6.95 \\
\hline
\end{tabular}




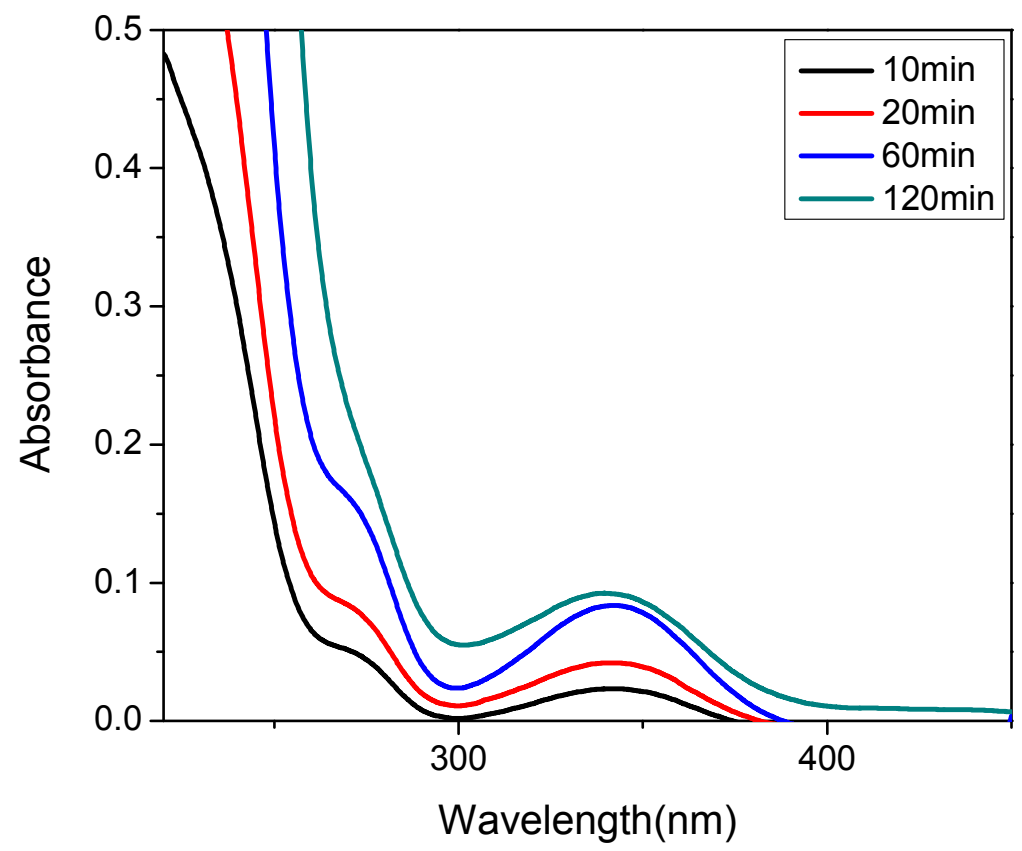

Supplementary Figure S5. UV-Vis spectra monitoring the coupling between the thiolated BSA (BSA-SH) and end-capped pyridine disulfide PNIPAAm due to the increased absorbance peak at $340 \mathrm{~nm}$ of the produced 2-mercaptopyridine. 


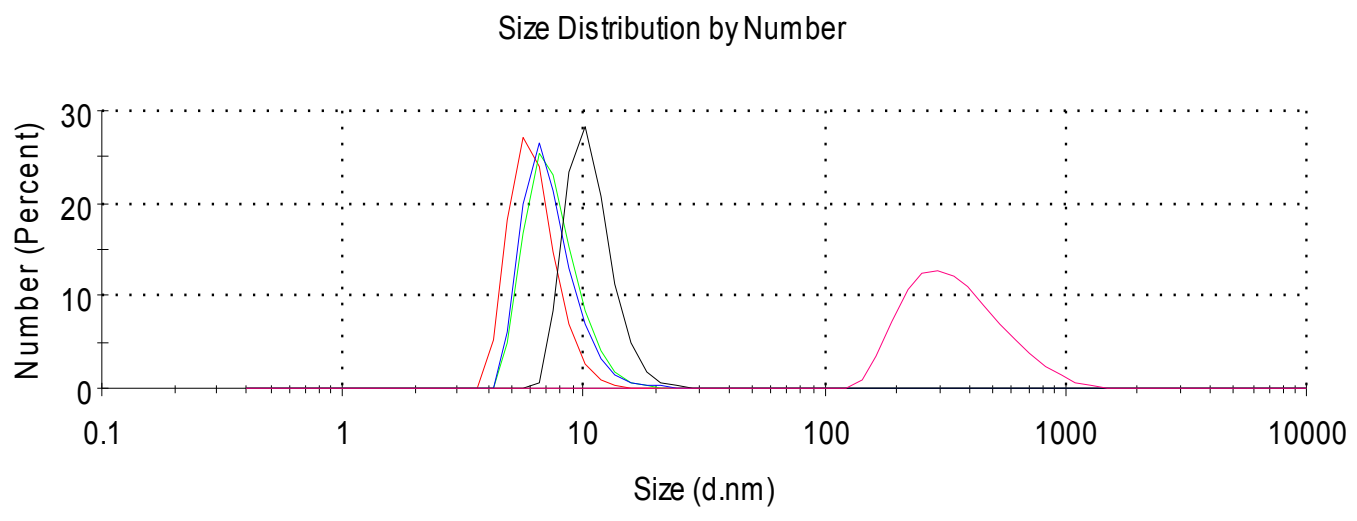

\begin{tabular}{lll} 
Record 17: BSA & Record 18: BSA-NH2 \\
Record 19: BSA-SH & Record 20: BSA-S-S-PNIPAAm(20C) \\
Record 21: BSA-S-S-PNIPAM(40C) & \\
\hline
\end{tabular}

Supplementary Figure S6. DLS profiles for aqueous BSA (red, $5.62 \mathrm{~nm}$ ), BSA-NH (green, $6.50 \mathrm{~nm}$ ), BSA-SH (blue, $6.50 \mathrm{~nm}$ ) and BSA-SH/PNIPAAm (black, $10.10 \mathrm{~nm}$ ) conjugates recorded at $20{ }^{\circ} \mathrm{C}$. Profile for aqueous BSA-SH/PNIPAAm (pink, 295.3 nm) at $40{ }^{\circ} \mathrm{C}$ is also shown. 


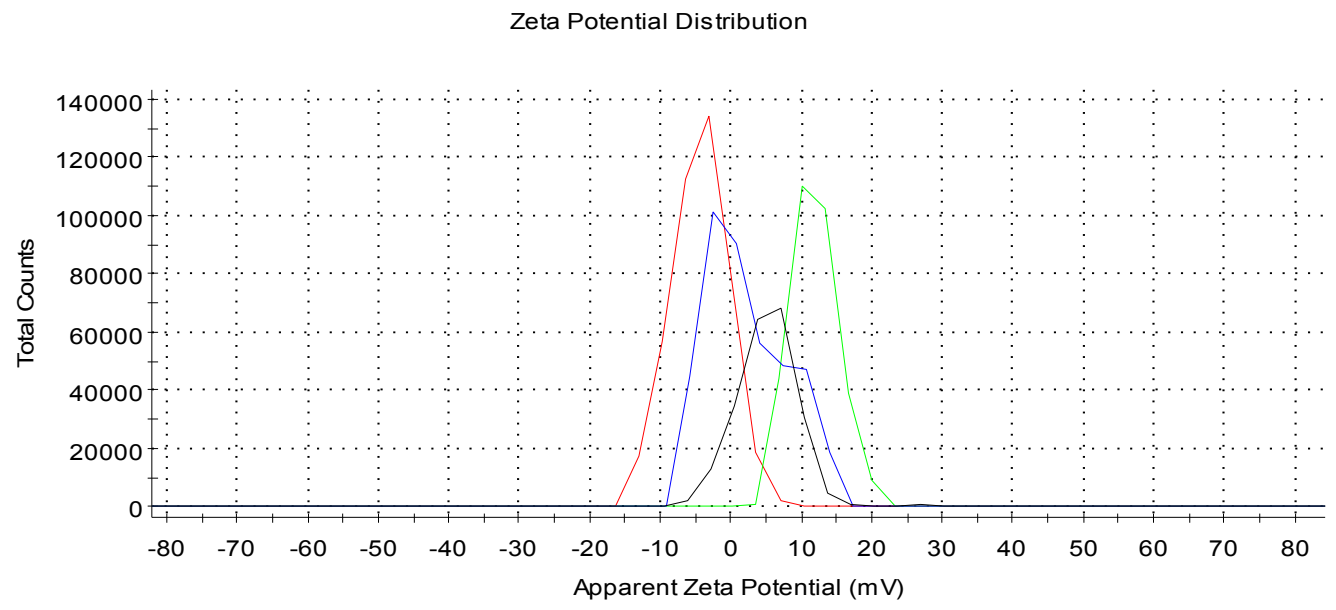

Supplementary Figure S7. Zeta potential measurements for BSA (red, -2.97 mV),

BSA-NH ${ }_{2}$ (green, $+10.2 \mathrm{mV}$ ), BSA-SH (blue, $-2.64 \mathrm{mV}$ ) and BSA-SH/PNIPAAm (black, $+7.02 \mathrm{mV}$ ) in $10.0 \mathrm{mM}$ PBS pH 8.0 buffer solution at room temperature. 

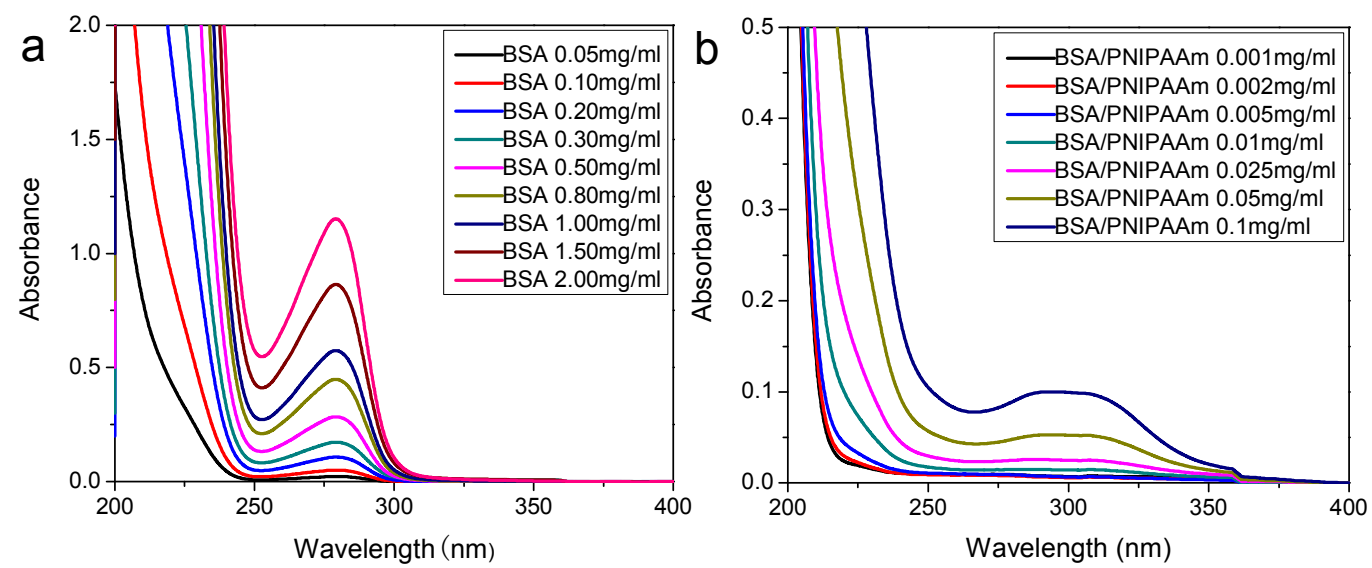

Supplementary Figure S8. (a, b) UV-Vis spectra of protein and protein-polymer conjugate at different concentration, respectively. 

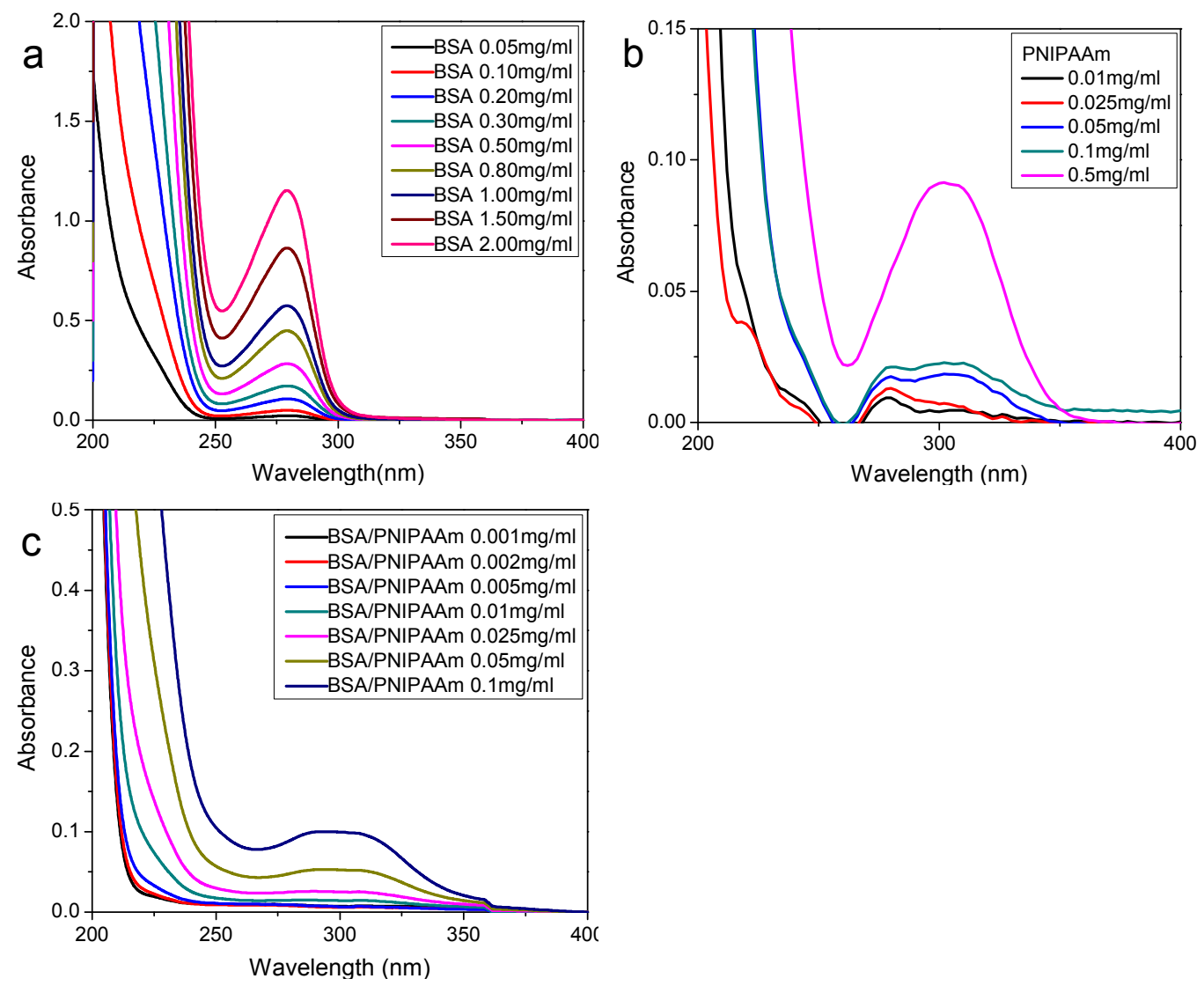

Numbers of PNIPAAm conjugated per BSA molecule:

\begin{tabular}{|c|c|c|c|c|c|c|}
\hline $\begin{array}{c}\text { BSA } \\
(\mathrm{mg} / \mathrm{ml})\end{array}$ & $\mathbf{A}_{300 \mathrm{~nm}}$ & $\begin{array}{c}\text { PNIPAAM } \\
(\mathrm{mg} / \mathrm{ml})\end{array}$ & $\mathbf{A}_{300 \mathrm{~nm}}$ & $\begin{array}{c}\text { BSA-S-S-P } \\
\text { NIPAAM } \\
(\mathbf{m g} / \mathrm{ml})\end{array}$ & $\mathbf{A}_{\mathbf{3 0 0 n m}}$ & $\begin{array}{c}\text { Number of polymer } \\
\left(\mathbf{A}_{B S A-S-S-P N I P A A M}-\mathbf{A}_{B S A}\right) \\
/ \mathbf{A}_{\text {PNIPAAM }}\end{array}$ \\
\hline & & 0.025 & 0.0071 & 0.025 & 0.0249 & \\
\hline 0.05 & 0.0227 & 0.05 & 0.018 & 0.05 & 0.0525 & 1.6526 \\
\hline 0.1 & 0.0507 & 0.1 & 0.0223 & 0.1 & 0.0994 & 2.1803 \\
\hline 0.2 & 0.108 & & & & & $\begin{array}{c}\text { average value } \\
1.91645\end{array}$ \\
\hline
\end{tabular}

Supplementary Figure S9. (a, b, c) UV-Vis spectra of protein, polymer and proteinpolymer conjugate at different concentration, respectively. The numbers of PNIPAAm conjugated per BSA molecule is summarized in the table, and there is 1.91645 
polymer units per protein-polymer conjugate in average, which is calculated with the formulas below.

$$
\text { Number ploymer }=\frac{A B S A-S-S-P N I P A A m-A B S A}{A P N I P A A m}
$$
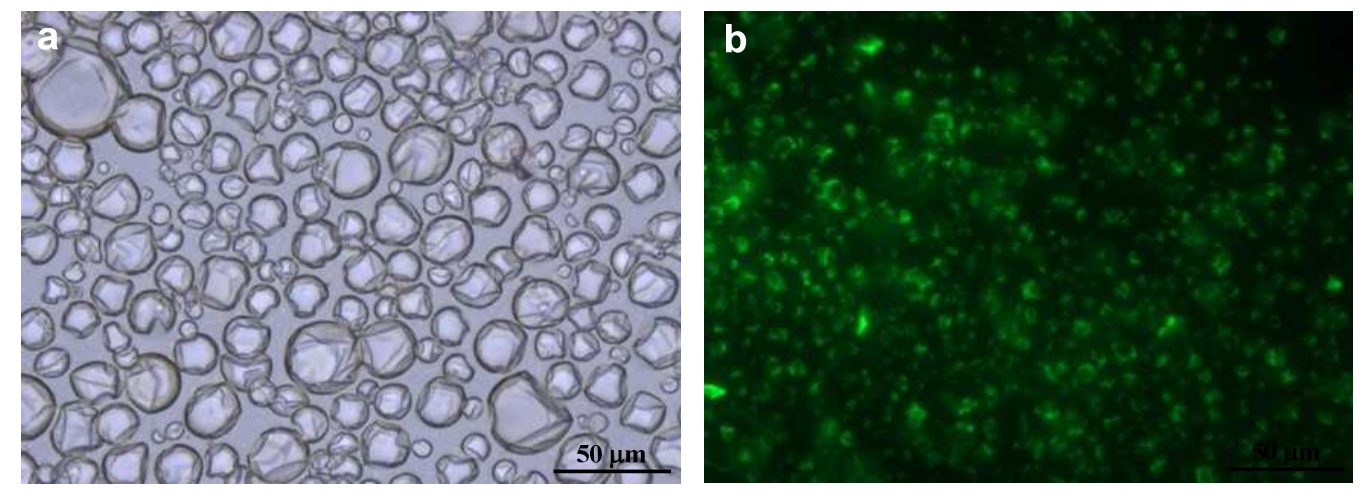

Supplementary Figure S10. (a) Optical microscope image and (b) fluorescence microscope image of BSA-SH/PNIPAAm proteinosomes encapsulated fluorescein isothiocyanate labelled dextran (FITC-Dextran MW $500 \mathrm{kDa}$ ) in oil after 1 hour drying in air, respectively. 

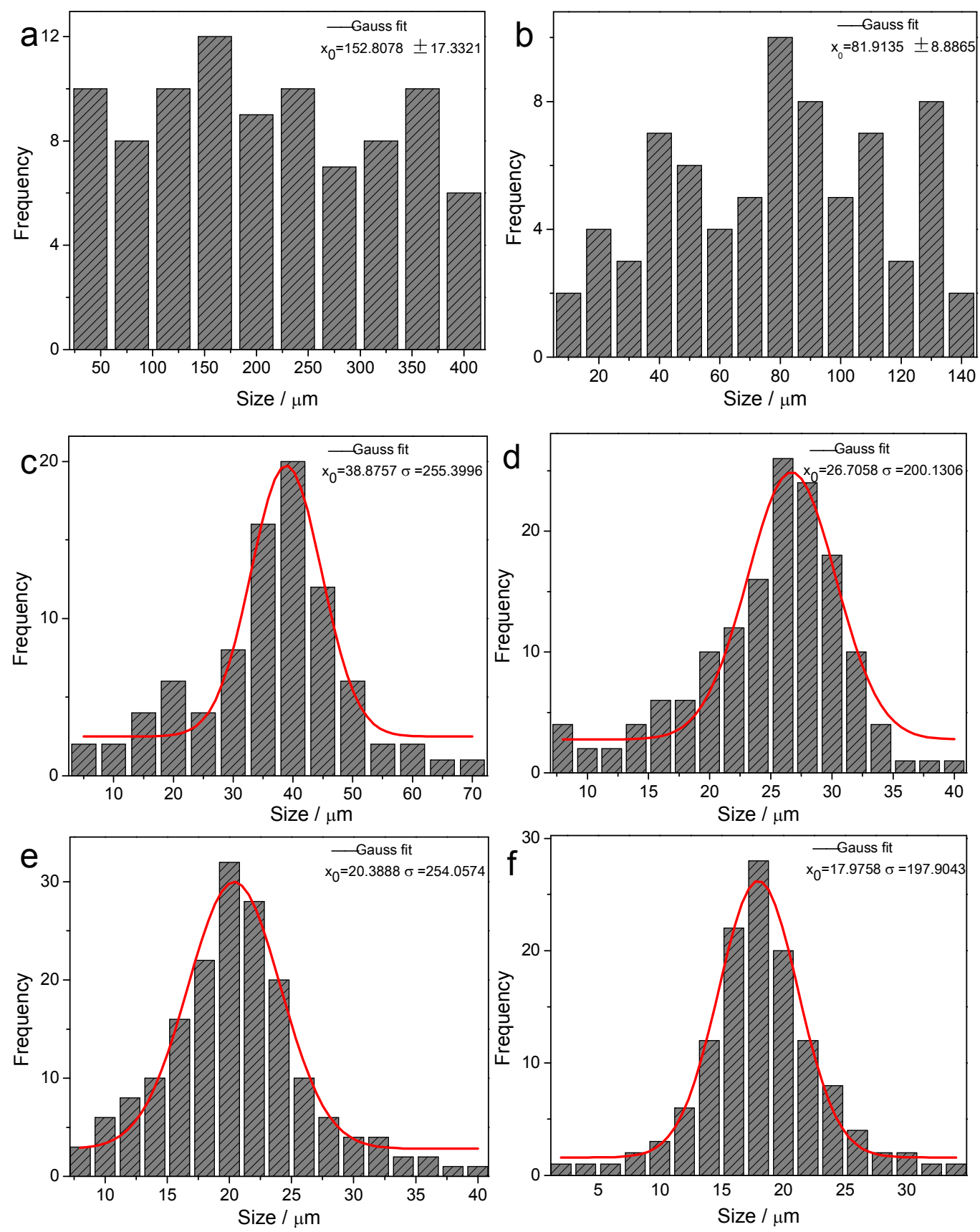

Supplementary Figure S11. (a-f) Particle size distribution of proteinosomes prepared at different concentrations of BSA-SH/PNIPAAm $(0.2,0.4,1.0,2.0,4.0$ and 8.0 $\mathrm{mg} / \mathrm{mL}$, respectively). 

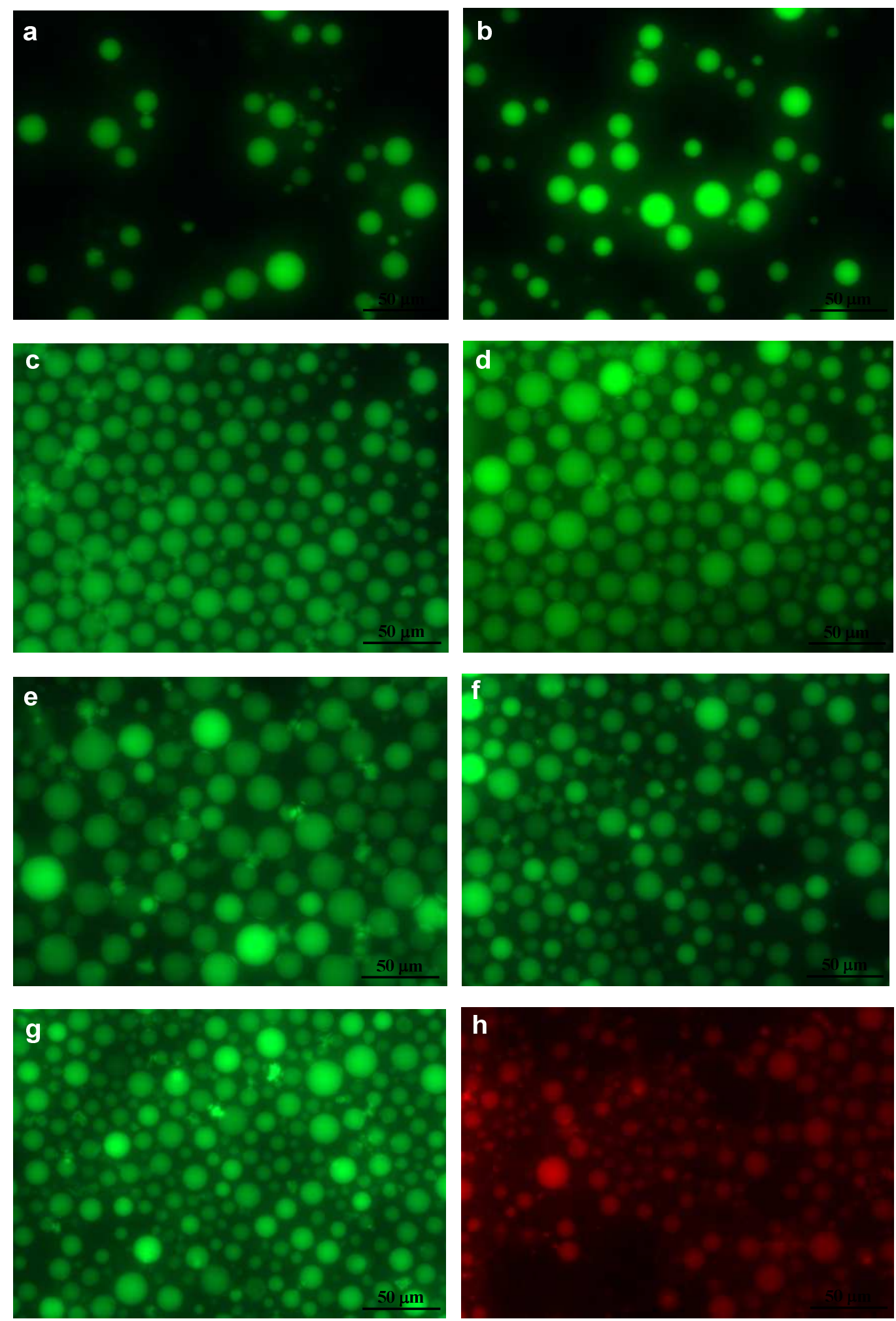

Supplementary Figure S12. (a-g) and (h) Fluorescence microscope image of BSA-SH/PNIPAAm proteinosomes after encapsulating fluorescein isothiocyanate (FITC) with 
different molecular weight in oil phase $(10 \mathrm{kDa}, 20 \mathrm{kDa}, 40 \mathrm{kDa}, 70 \mathrm{kDa}, 150 \mathrm{kDa}, 500 \mathrm{kDa}$, $2000 \mathrm{kDa})$ and rhodamine $6 \mathrm{G}(70 \mathrm{kDa})$ in oil, scale bars, $50 \mu \mathrm{m}$, respectively.
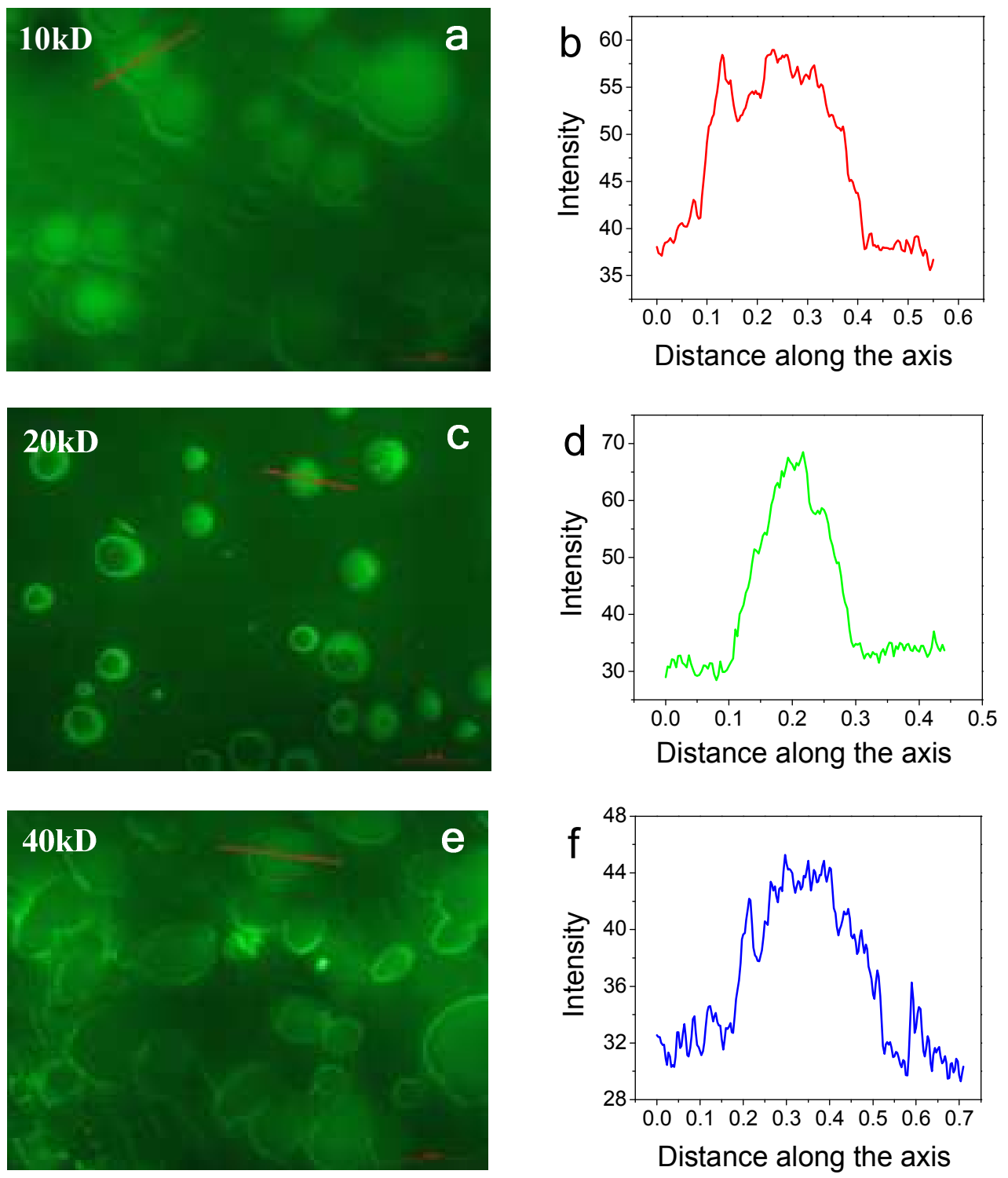

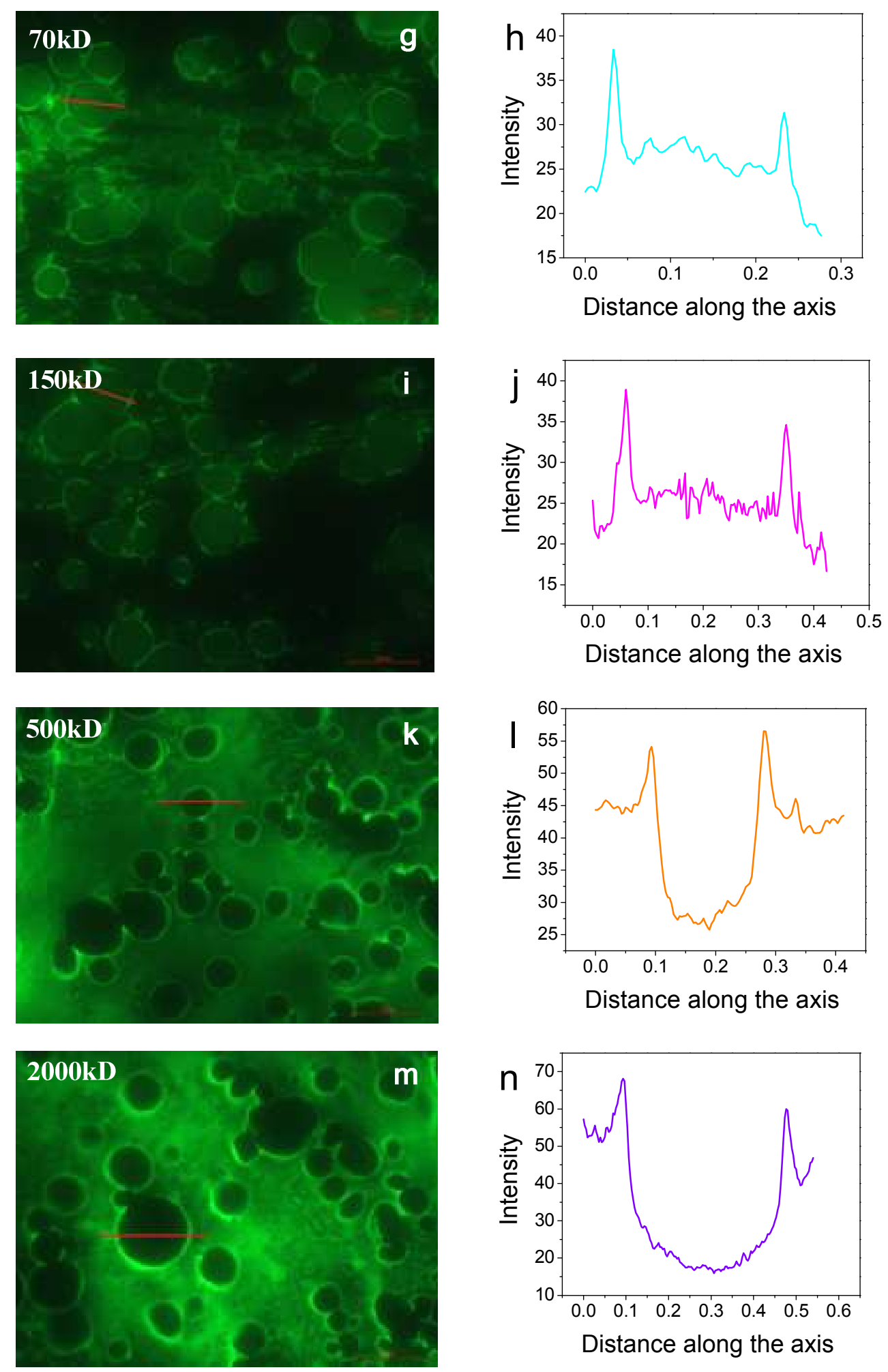

Supplementary Figure S13. Uptake studies for BSA-SH/PNIPAAm proteinosomes incubated in solutions of fluorescent-labeled dextrans (FITC-dextran) with molecular 
weights from 10 to $2000 \mathrm{kDa}$. The experiments were performed by mixing $10 \mu \mathrm{L}$ of $0.2 \mathrm{mg} / \mathrm{mL}$ FITC-dextran solution with $20 \mu \mathrm{L}$ of a proteinosome aqueous dispersion, and incubating the mixture at $25{ }^{\circ} \mathrm{C}$ for $30 \mathrm{~min}$. Uptake or exclusion of the FITC-dextran macromolecules was directly observed by a combination of fluorescence (a, c, e, g, i, k, m) microscopy images. The image pairs are for proteinosomes incubated at $25^{\circ} \mathrm{C}$ in the presence of FITC-dextran with a molecular weight of $10,20,40,70,150,500$ or $2000 \mathrm{kDa}$, respectively). (b, d, f, h, j, 1, n) Corresponding fluorescence line intensity profiles of selected proteinosomes shown in the fluorescence images. 